\title{
Precipitation rate spectra as dependent on dynamic forcing: application to probabilistic forecasting
}

\author{
N. P. Chakina, E. N. Skriptunova, and A. R. Ivanova \\ Hydrometeorological Research Centre of the Russian Federation, Moscow, Russia
}

Received: 27 June 2006 - Revised: 29 December 2006 - Accepted: 9 January 2007 - Published: 26 April 2007

\begin{abstract}
Occurrence frequencies, OF, of 12-h precipitation amounts, P, at stations in the former European USSR are displayed as dependent on dynamic forcing of vertical motions. The dynamic forcing is described by a "frontal parameter", $F$ (calculated in the points of objective analysis grid), which depends on the surface pressure field curvature and on the baroclinicity in the lower half of the troposphere. The precipitation rate spectra for 4 seasons, calculated from a large sample of data (7 years, about 650000 values of $P$ for one season), show a monotonous $\mathrm{OF}$ growth of all ranges of $\mathrm{P}>1 \mathrm{~mm} / 12 \mathrm{~h}$ with $\mathrm{F}$ increase. The growth is especially significant for heavy precipitation. As a result, $\mathrm{F}$ is shown to be an informative predictor of $\mathrm{P}$ spectrum or of probability of any given range of P. As a next step, two-dimensional spectra of precipitation occurrence frequency, as a function of $\mathrm{F}$ and $\mathrm{LNB}$, that is, OF (F, LNB), are calculated, LNB being the level of neutral buoyancy at the gridpoint, an estimate of grid-scale convective instability. On this basis, an approach to probabilistic forecasting is suggested.
\end{abstract}

\section{Introduction}

The vertical motions in the atmosphere are generally caused by a number of mechanisms which disturb the geostrophic and thermal wind balance: they include friction, release of convective and hydrodynamic instability, and inhomogeneous advection (frontogenesis and frontolysis). The latter mechanism plays a primary role in the frontal baroclinic zones by forcing transverse vertical circulations. They can be deep enough to embrace the whole troposphere and the lower stratosphere. The vertical motions in the transverse circulations are diagnostically related (Hoskins et al., 1978) to the characteristics of baroclinicity and of its time evolution (that is, of frontogenesis/frontolysis). Thus, dynamic forcing of vertical motions, especially in the baroclinic zones, can be estimated through diagnostics describing the mentioned "dynamic forcing factors". In the real frontal zones, both forcing factors act simultaneously, due to specific configuration of pressure field. So, typical cyclonic curvature of the latter ensures wind convergence and frontogenesis and thus ascending motions in the warm airmass.

In general, the precipitation rate can be considered as an integral indicator of ascending motions in the lower half of the troposphere. The 12-h precipitation amounts, as independently measured at the stations, can be compared against the diagnostics calculated from the objective analysis data. Thus, the diagnostics, if they describe adequately the dynamic forcing, should be statistically related to the precipitation rate (and its occurrence frequency, OF).

In the paper, a minimum set of such diagnostics is considered, and statistical relationships are presented in the form of precipitation rate spectra as dependent on dynamic forcing characteristics. The relationships are found close enough to be applied for probabilistic forecasting of precipitation spectra and of precipitation rates exceeding a given threshold.

\section{Data and diagnostics}

The 12-h (daytime and nighttime) precipitation amounts, $\mathrm{Pmm} / 12 \mathrm{~h}$, at the stations in the former European USSR (about 1300 stations) are used for 7-year period (1999-2005) as classified into 4 ranges of intensity: 0-0.2 ("no precipitation"), 0.3-1.0 ("very slight"), 1.1-2.0 ("slight"), 2.1-6 ("moderate"), 6-19 ("heavy") and $>19$ ("very heavy"). Precipitation $\mathrm{P}>1 \mathrm{~mm} / 12 \mathrm{~h}$ is considered "significant". The $\mathrm{P}$ data set for any season contains about 650000 of observations.

Correspondence to: N. P. Chakina

(chakina@mecom.ru)

Published by Copernicus GmbH on behalf of the European Geosciences Union. 


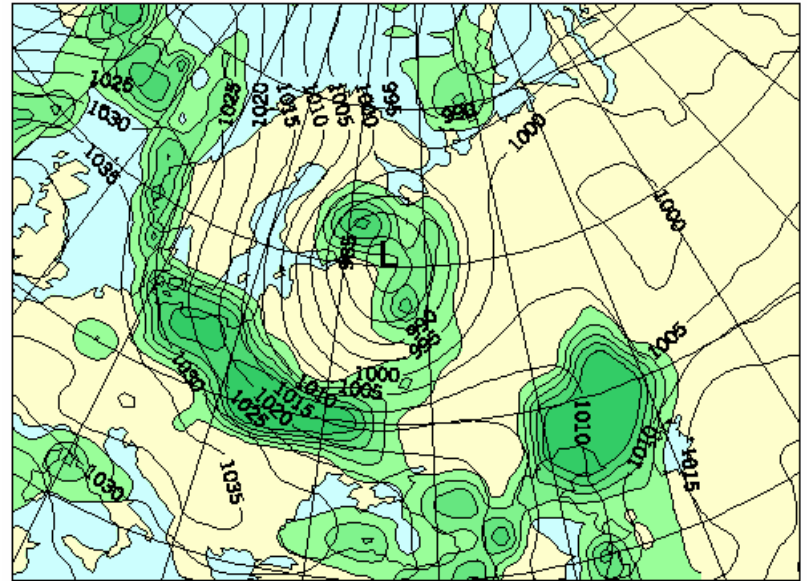

Fig. 1. Example of frontal zones detected as zones of large $F(>20)$, 16.11.2001 00:00 UTC. Surface pressure contours (hPa) and F contours, with increment of 20 , are given.

To compute the diagnostics, objective analysis, OA, data (the scheme used in the Hydrometeorological Center of Russia) in the geographic gridpoints $\left(2.5 \times 2.5^{\circ}\right)$ are used for the same period (about 190000 gridpoints for a season). The following diagnostics are used in the analysis:

1. Frontal parameter, $\mathrm{F}$ (dimensionless), as a measure of frontal forcing effects. The parameter (Chakina et al., 1998, 2000) represents a generalization of the approach developed in Huber-Pock and Kress (1989). In fact, the parameter $\Psi$, as used by F. Huber-Pock and $\mathrm{Ch}$. Kress, represented a characteristic of baroclinicity in the lower half of the troposphere and has been designed to reveal the zones of maximum baroclinicity and location of surface front line with respect to the zones. The frontal parameter, F, determined as a combined characteristic of baroclinicity and of pressure field topography, acquired a new (with respect to $\Psi$ ) property of monotonic increase of $\mathrm{P}$ occurrence frequency, $\mathrm{OF}$, with increasing $F$. The algorithm of calculation became more complicated: an objective classification of pressure field local topography is included. Namely, 23 classes of the latter are suggested: 8 sectors and centers of both high and low; trough; ridge; saddle; rectilinear isobars; and low-gradient field. The ranges of $\mathrm{F}$ have been statistically determined (Chakina et al., 2000) for airmass conditions with low baroclinicity $(\mathrm{F}<20)$, diffuse frontal zones $(20 \leq \mathrm{F}<40)$, active frontal zones $(40 \leq F<60)$, and sharp fronts $(F \geq 60)$. An example of $F$ diagnostic field is shown in Fig. 1.

2. Scalar frontogenetic function, $\mathrm{FG},{ }^{\circ} \mathrm{C} /(12 \mathrm{~h} \times 500 \mathrm{~km})$, a direct estimate of frontogenesis $(\mathrm{FG}>0)$ and frontolysis $(\mathrm{FG}<0)$ at $850 \mathrm{hPa}$ level.

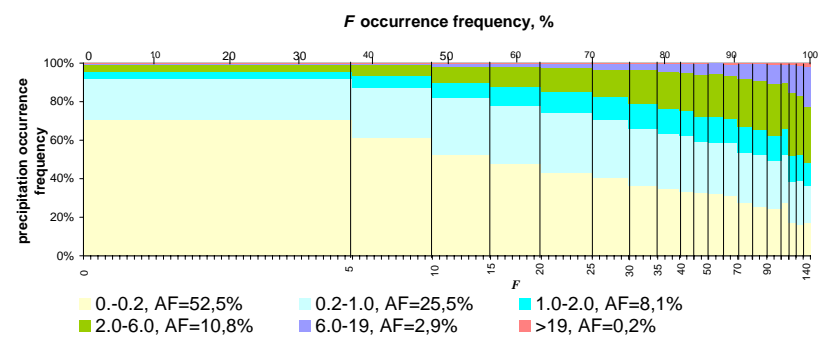

Fig. 2. Spectrum of occurrence frequencies of 12-h precipitation amounts, $\mathrm{P}$, as dependent on frontal parameter, $\mathrm{F}$ ( 7 winters, 636992 precipitation data). The values of $F$ (lower horizontal scale) are shown according to their occurrence frequency (upper horizontal scale, \%). AF is averaged occurrence frequency for the corresponding range of $\mathrm{P}$.

3. Level of neutral buoyancy, LNB (km), calculated at the OA gridpoints, - a characteristic of grid-scale static instability. Strictly speaking, LNB must be considered to describe "convective forcing" and not "dynamic" one. Still, with respect to individual parcel involved into a convective updraft, the ascent is forced by the convective cloud dynamics. The values of $\mathrm{LNB}<4$, $4 \leq \mathrm{LNB}<8$, and $\mathrm{LNB} \geq 8 \mathrm{~km}$ are considered as corresponding to shallow, moderate, and deep convection, respectively. Of course, a significant part of convective activity (subgrid convection) cannot be taken into account in our case.

4. Height of dynamic tropopause, TR (hPa), calculated at the OA gridpoints as the level of $\mathrm{PV}=1$ pvu. TR is considered as an indicator of deep transverse circulations in the baroclinic zones.

To calculate the diagnostics, the following OA data are used: pressure (height), temperature, and wind at all tropospheric and lower stratospheric standard levels; humidity at the surface and at 925, 850, 700, $500 \mathrm{hPa}$ levels. Note that vertical motion or precipitation data are not included. Two diagnostics, FG and TR, are completely independent on humidity. The frontal parameter includes equivalent temperature and thus depends on humidity but slightly. LNB is the only diagnostic whose dependence on humidity is significant (because the condensation level is calculated using humidity in the ascending air parcel).

\section{Results}

\subsection{Precipitation spectra}

The calculated diagnostics are compared against the precipitation 12-h amounts at the stations within the gridsquare. With the raingauge network being sparse enough, only the gridsquares with at least one observing station for a separate 

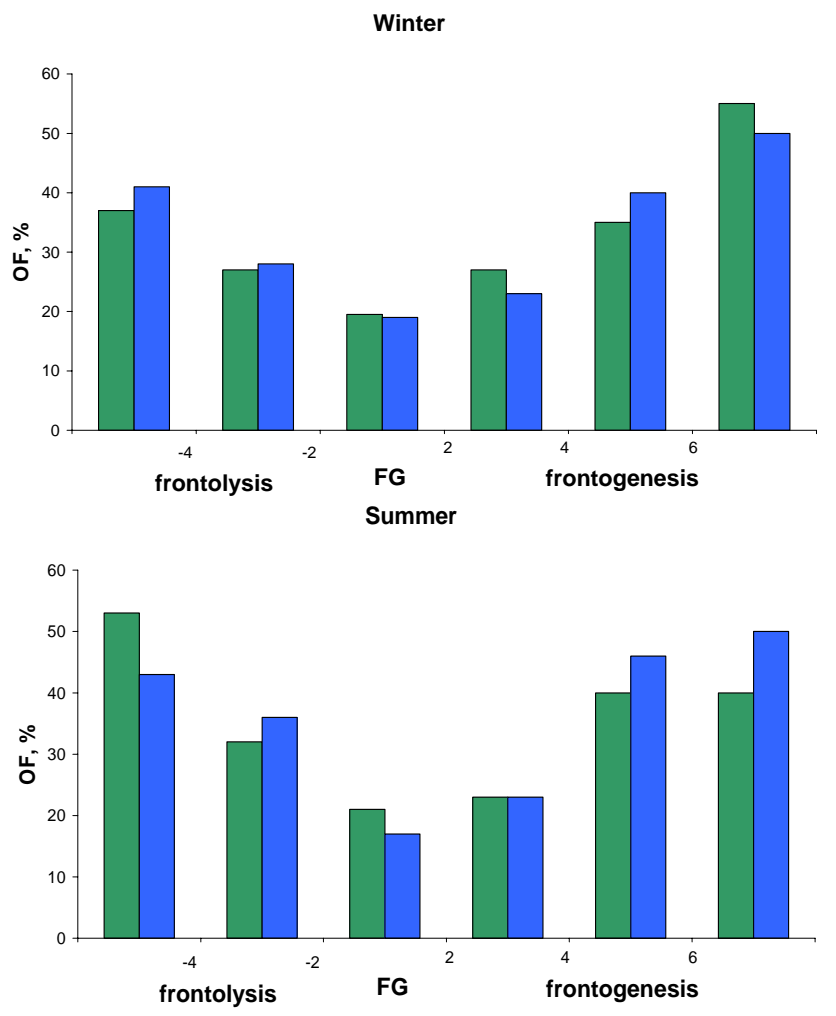

Fig. 3. Dependences of night (blue columns) and day (green columns) precipitation $>1 \mathrm{~mm} / 12 \mathrm{~h} \mathrm{OF}$ on frontogenetic function at $850 \mathrm{hPa}, \mathrm{FG}^{\circ} \mathrm{C} /(12 \mathrm{~h} \times 500 \mathrm{~km})$.

12-h period are included into the analysis. The results are obtained for each of 4 seasons (Chakina et al., 2001). In Fig. 2, the precipitation OF spectrum is displayed as calculated from the data for 7 winters (total of 189735 gridsquares and 636992 precipitation reports). The reports on "no precipitation" are included into the range of $0-0.2 \mathrm{~mm} / 12 \mathrm{~h}$. It can be seen that dependence of $\mathrm{P}$ on $\mathrm{F}$ is practically monotonous, and for moderate and especially heavy precipitation, dependence of $\mathrm{OF}$ on $\mathrm{F}$ is much stronger than for light one. Even low baroclinicity (F from 5 to 20) affects $\mathrm{P}$, which grows continuously in the whole range of F. Note that, in total for every season, OF of "no precipitation" is not zero even for large F. (For example, in Fig. 2, averaged occurrence frequency of $\mathrm{P}=0$ to $0.2 \mathrm{~mm} / 12 \mathrm{~h}$ is $52.5 \%$, while, with growing $\mathrm{F}$, occurrence frequency of this range of $\mathrm{P}$ decreases from about $70 \%$ for $\mathrm{F}<5$ to less than $30 \%$ for $\mathrm{F}>100$.) In fact, frontal forcing, though quite significant, is not the only factor of precipitation generation. This can be seen also from the results for other diagnostics. For other seasons, the spectra are analogous to that shown in Fig. 2, with differences in OF of both F and P.

The effect of frontogenesis, as estimated by FG, is presented in Fig. 3 for $\mathrm{P}>1 \mathrm{~mm} / 12 \mathrm{~h}$. In fact, OF of all ranges of $\mathrm{P}$ grow with $|\mathrm{FG}|$. The growth is faster for heavier precipitation and also faster in the cases of $\mathrm{FG}<0$ than in those

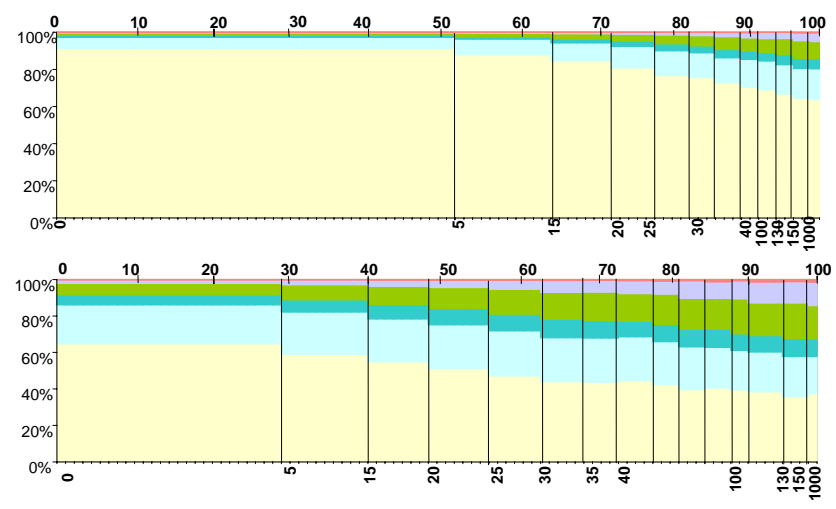

Fig. 4. As in Fig. 2, but for the subsets of $\mathrm{LNB}=0$ (upper panel) and $\mathrm{LNB}>0$ (lower panel) in autumn.

of $\mathrm{FG}>0$. However, the subsets of significant non-zero $|\mathrm{FG}|$ are not large in all seasons (of order of 18-25\% of the corresponding sets, frontogenesis being 3.5 times more frequent than frontolysis with the same $|\mathrm{FG}|)$. This fact, which is evidently associated with features of the accepted way of FG calculation, leads to underestimation of FG informativity about $\mathrm{P}$ occurrence frequency distribution.

The dependence of precipitation OF on TR (not shown) is well defined enough, showing increased OF mainly under low tropopause $(\mathrm{TR}>400 \mathrm{hPa})$. The heavy precipitation $\mathrm{OF}$ is 2 (winter) and 3 (summer) times higher under low tropopause than under high $(\mathrm{TR}<200 \mathrm{hPa})$ one. Indeed, the tropopause folds and funnels are associated with the atmospheric fronts (usually, with cold ones). However, high domes and deep folds of the tropopause are not frequent (in winter 3 to $13 \%$ of the whole sample, respectively, in summer -3 to $7 \%$ ). To a certain extent, the low percentage is due to low resolution of the $\mathrm{OA}$ data.

The $\mathrm{P}$ spectra for the subsets with convective instability $(\mathrm{LNB}>0)$ and stability $(\mathrm{LNB}=0)$ are shown in Fig. 4. For all the seasons, 2-D spectra have been calculated on the F,LNB plane (Chakina and Skriptunova, 2006). Note that convective instability itself is, to a large extent, a result of frontal forcing. Considering OF of LNB as dependent on F (not shown), it is found that in summer, when the impact of thermal convection is maximum, $29 \%$ of all cases of convective instability and $37 \%$ of deep one are forced by frontal effects.

\subsection{Noises}

As it can be seen in Fig. 4 (upper panel), under conditions of convective stability and vanishing baroclinicity $(\mathrm{F}<5)$, a certain percentage of precipitation (about $10 \%$ of all the cases) still occurs. Assuming that frontal and convective forcing are the main grid-scale factors of precipitation generation, one can conclude that the mentioned subset of $P$ cases cannot be explained by these factors, and thus must be interpreted 


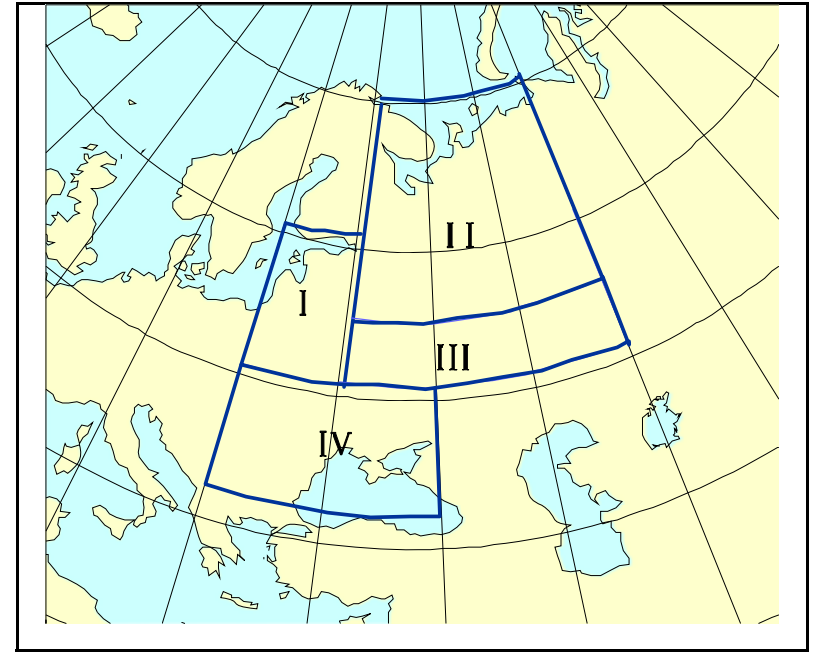

Fig. 5. Regions I-IV.

as "noise" within the framework of two-parameter (F, LNB) approach. The noise is caused by unaccounted forcing factors (including subgrid ones) and by all kinds of errors. The noise level in the precipitation $\mathrm{OF}$ varies from about $7 \%$ in summer to $15 \%$ in winter. The noise subsets consist mainly of very slight and slight precipitation (65.3 to $89.8 \%$ of the cases, depending on season). Occurrence frequencies of $\mathrm{P}>6 \mathrm{~mm} / 12 \mathrm{~h}$ in the subsets are very low (one order of magnitude lower than in the total sets).

Assuming that the noises of the same origin and level exist within the total ranges of $\mathrm{F}$ and $\mathrm{LNB}$, one can subtract the noises from the total 2-D spectrum and, in this way, obtain the spectrum free of noises, - in other words, the spectrum of precipitation generated by the two forcing factors. The calculation shows that in such spectra, 78.7 to $85.8 \%$ (depending on season) of all cases of precipitation $>6 \mathrm{~mm} / 12 \mathrm{~h}$ are retained, as well as 75.4 to $79.6 \%$ of $\mathrm{P}>1 \mathrm{~mm} / 12 \mathrm{~h}$.

Thus, it can be concluded that precipitation $>1 \mathrm{~mm} / 12 \mathrm{~h}$ and especially $>6 \mathrm{~mm} / 12 \mathrm{~h}$ are determined mainly by frontal and convective forcing and thus can be diagnosed (or "predicted" within the perfect prognosis, PP, approach) with a significant efficiency on the basis of two diagnostics ( $F$ and LNB) calculated from the OA data.

\subsection{Informativity of the diagnostics as precipitation predic-} tors

In the simplest case, discrimination between occurrence and non-occurrence of $\mathrm{P}$ exceeding a given value (1 or $6 \mathrm{~mm} / 12 \mathrm{~h}$ ) can be carried out by using threshold values of a single diagnostic or of a pair of them. Efficiency of the discrimination can be estimated by the total skill score (TSS).

To include into consideration certain regional features, the whole area is divided into 4 parts (Fig. 5), for which, TSS values for every season and $\mathrm{P}>6 \mathrm{~mm} / 12 \mathrm{~h}$ are presented in Ta- ble 1 (insignificant values of TSS are shown by dashes). The highest TSS practically everywhere and in all seasons correspond to the pair of F, LNB. However, in winter and summer, respectively, informativity of the TR and FG in combinations with $\mathrm{F}$ and LNB is high enough, too.

\subsection{Application to probabilistic forecasting}

Two possibilities can be considered of using the presented results for this purpose.

1. Forecasting of the whole spectrum of P probabilities (instead of a single "most likely" value). Probabilities of $\mathrm{P}$ ranges can be determined from the precipitation rate 2-D spectra. For instance, the results shown in Fig. 4, upper panel, can be used for this purpose in the case of $\mathrm{LNB}=0$. The $\mathrm{OF}$ in the 2-D spectra can be used to approximate the probabilities with a good accuracy, because the sample of the used data is large and because it is pointed out that the spectra calculated for the periods of $7,6, \ldots, 3$ years differ from each other but slightly: so, the corresponding changes in TSS values for F, LNB are within $3 \%$.

2. Forecasting of probability for a given $\mathrm{P}(>1$ or $>6 \mathrm{~mm} / 12 \mathrm{~h}$ ), on the same basis of predicted F, LNB in the gridpoint and the 2-D spectra.

Efficiency of the forecasting evidently depends on accuracy of F, LNB computed from the output data of the numerical model under use.

For a more convenient interpretation of the results for the predictands with usually low occurrence frequency (e.g., $\mathrm{P}>6 \mathrm{~mm} / 12 \mathrm{~h}$, whose season-averaged occurrence frequency, $\mathrm{k}$, is of order of few percent), so called "virtual probability $\mathrm{VP}=\mathrm{K} /(\mathrm{K}+\mathrm{k})$ can be introduced, $\mathrm{K}$ being the predicted probability, so that $\mathrm{VP}=0.5$ when $\mathrm{K}=\mathrm{k}$ and $\mathrm{VP} \rightarrow 1$ when $\mathrm{K}$ grows.

Accuracy of VP calculated from the numerical forecasts is estimated for several models whose output data are used operatively in the Hydrometeorological Centre of Russia. The UKMO global model is found to produce the lowest level of VP field smoothing (as compared with the objective analysis), - that is, about 5-6\% in the VP maxima.

It is to note that the predictors do not include the model precipitation or vertical motions, whose accuracy of simulation is often insufficient or doubtful. Moreover, the dependence of F, LNB on humidity is weak enough. These features represent an advantage of the proposed approach, as compared by other ones (e.g., Applequist, 2002; Bremnes, 2004; Yuan et al., 2005).

\section{Conclusions}

In this paper, a minimum set of 4 diagnostic characteristics of vertical motion dynamic forcing is considered to estimate 
Table 1. Informativity (TSS) of the diagnostics computed from the objective analysis data as predictors (PP approach) of $\mathrm{P}>6 \mathrm{~mm} / 12 \mathrm{~h}$ : 7 years, 4 regions of the former European USSR.

\begin{tabular}{|c|c|c|c|c|c|c|c|c|c|c|c|c|c|c|c|c|c|}
\hline & & \multicolumn{4}{|c|}{$\mathrm{F}$} & \multicolumn{4}{|c|}{ LNB } & \multicolumn{4}{|c|}{ FG } & \multicolumn{4}{|c|}{ TR } \\
\hline & & Win & Spr & Sum & Aut & Win & $\mathrm{Spr}$ & Sum & Aut & Win & Spr & Sum & Aut & Win & $\mathrm{Spr}$ & Sum & Aut \\
\hline \multirow{4}{*}{$\mathrm{F}$} & I & .49 & .48 & .30 & .45 & .51 & .54 & .38 & .53 & .50 & .50 & .32 & .46 & .50 & .49 & .31 & .48 \\
\hline & II & .48 & .44 & .33 & .46 & .50 & .49 & .40 & .49 & .49 & .47 & .34 & .46 & .50 & .45 & .33 & .46 \\
\hline & III & .53 & .50 & .33 & .51 & .54 & .54 & .39 & .55 & .56 & .51 & .34 & .53 & .55 & .51 & .34 & .52 \\
\hline & IV & .50 & .36 & - & .45 & .52 & .46 & .39 & .52 & .52 & .38 & .26 & .46 & .52 & .38 & .26 & .46 \\
\hline \multirow{4}{*}{ LNB } & I & & & & & - & - & .32 & .38 & .29 & .41 & .36 & .42 & - & .32 & .33 & .38 \\
\hline & II & & & & & - & - & .29 & - & - & .34 & .34 & .30 & - & - & .30 & - \\
\hline & III & & & & & - & .33 & .29 & .30 & .32 & .42 & .35 & .41 & - & .33 & .30 & .30 \\
\hline & IV & & & & & - & .37 & .37 & .35 & .35 & .41 & .38 & .40 & - & .38 & .37 & .35 \\
\hline \multirow{4}{*}{ FG } & I & & & & & & & & & - & - & - & - & .27 & .27 & - & - \\
\hline & II & & & & & & & & & - & - & - & - & - & - & - & - \\
\hline & III & & & & & & & & & .31 & .26 & - & .28 & .35 & .28 & - & .30 \\
\hline & IV & & & & & & & & & .31 & - & - & - & .33 & - & - & - \\
\hline
\end{tabular}

their effects on precipitation. The statistical relationships between the precipitation rate (12-h amount) occurrence frequencies and the diagnostics are presented in the form of precipitation rate, $\mathrm{P}$, spectra as dependent on dynamic forcing characteristics. The following results of the analysis can be formulated.

1. The frontal effects (baroclinicity and pressure field curvature), as described by frontal parameter, $\mathrm{F}$, represent a primary factor of precipitation forcing. The $\mathrm{P}$ occurrence frequency spectra, computed for the former European USSR and for its regions, provide reliable estimates of precipitation probability distribution within the gridsquare, as dependent on $\mathrm{F}$ in the gridpoint. The heaviest precipitation, the fastest is its OF growth with $F$ in all seasons, especially in winter. As a single predictor of precipitation, $\mathrm{F}$ is informative (in terms of TSS) in all seasons.

2. Convective instability is, to a large extent, forced by frontal effects. However, convective forcing itself plays a significant role, so that LNB is informative as a single predictor of precipitation in all seasons but winter. Combination of $\mathrm{F}$ and LNB provides the highest TSS almost everywhere the year round.

3. The subsets of precipitation cases corresponding to vanishing baroclinicity, zero or anticyclonic curvature of pressure field, and stable stratification, in the 2parametric $(\mathrm{F}, \mathrm{LNB})$ consideration represent levels of noises, caused by unaccounted forcing factors and by all kinds of errors. The noise levels vary from $6.9 \%$ in summer to $15 \%$ in winter. In total, 78.7 to $85.8 \%$ (depending on season) of all cases of precipitation $>6 \mathrm{~mm} / 12 \mathrm{~h}$ are determined by the two forcing factors, described by $\mathrm{F}$ and LNB, - that is, by frontal and convective effects.

4. The 2-D spectra of $P$ can be used to forecast, with a significant efficiency, the $\mathrm{P}$ probability distribution within the gridsquare, on the basis of F, LNB values calculated from numerical model output data in the gridpoint. Another approach consists of predicting, on the same basis, probability distribution over an area for a given range of precipitation. Note that the predictors F, LNB do not include simulated precipitation or vertical motions; also, dependence of predictors on humidity is weak enough.

Acknowledgements. This research was supported by the Russian Foundation for Basic Research (Grants 01-05-64271, 04-0564646).

Edited by: S. C. Michaelides and E. Amitai

Reviewed by: anonymous referees

\section{References}

Applequist, S., Gahrs, G. E., Pfeffer, R. L., and Niu, X. F.: Comparison of methodologies for probabilistic quantitative precipitation forecasting, Wea. Forecast., 17, 3, 783-799, 2002.

Bremnes, J. B.: Probabilistic forecasts of precipitation in terms of quantiles using NWP model output, Mon. Wea. Rev., 132, 1, 338-347, 2004.

Chakina, N. P., Kalugina, G. Yu., Skriptunova, E. N., and Ivanova, A. R.: Subjective and objective analyses of atmospheric fronts. Pt 1. Objective characteristics of hand-drawn fronts, Russ. Meteorol. Hydrol., 7, 19-23. Pt 2. Objective detection of frontal zones, Ibid., 8, 1-10, 1998. 
Chakina, N. P., Skriptunova, E. N., and Ivanova, A. R.: The atmospheric front objective analysis and estimation of its efficiency, Ibid., 7, 5-16, 2000.

Chakina, N. P., Skriptunova, E. N., and Ivanova, A. R.: Estimation of precipitation generation factors from objective analysis data, Ibid., 5, 22-34, 2001.

Chakina, N. P. and Skriptunova, E. N.: Precipitation occurrence frequency spectra as dependent on frontal effects and grid-scale convective instability in the former European USSR, Ibid., 4, 5$18,2006$.
Huber-Pock, F. and Kress, Ch.: An operational model of objective frontal analysis based on ECMWF products, Meteorol. Atmos. Phys., 40, 2, 170-180, 1989.

Hoskins, B. J., Draghici, I., and Davies, H. C.: A new look at the omega-equation, Quart. J. Roy. Meteorol. Soc., 104, 1, 31-38, 1978.

Yuan, H., Mullen, S. L., Gao, X., and Juang, H.-M. H.: Verification of probabilistic quantitative precipitation forecasts over Southwest United States during winter 2002/03 by the RSM ensemble system, Mon. Wea. Rev., 133, 1, 279-293, 2005. 